\title{
TIPOGRAFIAS E TIPÓGRAFOS EM PERNAMBUCO, 1815-1824
}

\author{
Mário Fernandes Ramires*
}

RESUMO: O presente artigo possui como objetivo analisar as tipografias e tipógrafos existentes em Pernambuco no primeiro quartel do século XIX, bem como o papel desses centros propagadores de notícias e de opiniões sobre as transformações políticas e sociais que estavam ocorrendo então. Para tanto, foi feito o estudo das condições materiais, características da mão de obra e do funcionamento das tipografias, assim como a análise biográfica dos responsáveis por esses locais propagadores de notícias que funcionaram entre os anos de 1815 e 1824 . É notável a existência de um aparato tipográfico, que produziu diversos periódicos ligados a grupos de redatores, de acordo com seus ideais políticos e percebeu-se o surgimento de uma cultura impressa em Pernambuco, decisiva para a Independência e formação do Estado Nacional do Brasil.

PALAVRAS CHAVE: História da imprensa; Pernambuco; Século XIX; Independência do Brasil.

\section{Printing and printers in Pernambuco, 1815-1824.}

ABSTRACT: This article analyzes the chief characteristics of printing in the northeastern province of Pernambuco in Brazil in the nineteenth century as well as its role in disseminating news and opinions on political and social transformations in the period. It explores material conditions, labour and the operational characteristics of printing. The period considered is between 1815 when the first printing press was brought to the province, and 1824 when there were already several periodicals published in the region and a strong oppositional movement, the Confederation of the Equator, which challenged the established power in Rio de Janeiro using newspapers as an important tool in transmitting their ideas.

KEY WORDS: history of the press, Pernambuco, nineteenth century, Independence of Brazil.

\section{Tipografías y tipógrafos en Pernambuco, 1815-1824}

RESUMEN: El artículo tiene el objetivo analisar las tipografías y tipógrafos en Pernambuco en las primeras décadas del siglo XIX y, también el papel de estos centros propagadores de noticias y de opiniones sobre las transformaciones políticas y sociales que ocurrían en aquel tiempo. Por lo tanto, se hizo el estudio de las condiciones materiales, características de la mano de obra y del funcionamiento de las tipografías y el análisis biográfica de los responsables por esos locales propagadores de noticias que han funcionado entre los años 1815 y 1824. Es notable la existencia de un aparato tipográfico que produjo diversos periódicos relacionados con grupos de redactores, de acuerdo con sus ideales políticos. Aun percibimos el surgimiento de una cultura impresa en Pernambuco, muy importante para la Independencia y formación del Estado Nacional de Brasil.

PALAVRAS-CLAVE: Historia de la imprenta; Pernambuco; Siglo XIX; Independencia de Brasil.

*Mestre em História pela Universidade Federal de São Paulo (Unifesp). Professor da Universidade Nove de Julho (Uninove) e da Faculdade Flamingo. Contato: Universidade Nove de Julho, R. Itauna, 74, Vila Maria Baixa, 02111-030, São Paulo-SP, Brasil. professormariomfr@ hotmail.com. 


\section{Introdução}

Fazendo parte de um universo de profundas transformações sociais e políticas, foram diversos os debates e posicionamentos políticos surgidos em Pernambuco quando estava ocorrendo a ruptura entre Brasil e Portugal, um acontecimento marcante para a queda do Antigo Regime no continente americano. Esses debates ocorriam por meio da oralidade, manifestações artísticas ${ }^{1}$ e também por meio da palavra impressa, essa última destacadamente crescente até o ano de 1824, o que pode ser percebido pelo aumento do número de periódicos surgidos na província a partir de $1821^{2}$. No entanto, já no ano de $1817^{3}$, quando houve o movimento insurrecional e a nomeação do governo republicano na província, alguns panfletos já haviam sido impressos na primeira tipografia adquirida por um particular em Pernambuco no ano de 1815, que só seria utilizada dois anos depois, conforme será visto adiante.

As novas condições de sociabilidade, comuns ao contexto do que viria a se consolidar como modernidade ${ }^{4}$ na América Ibérica, trouxeram a possibilidade de circulação dos ideais políticos por meio da palavra impressa e os cafés, lojas, praças se tornaram locais onde se debatia a política e os rumos que a nação deveria seguir. Dessa maneira, é possível perceber a participação de um grande número de pessoas nos debates políticos veiculados pelos impressos durante o processo de ruptura com o Antigo Regime e surgimento de uma sociedade pautada em ideais liberais, iluministas, constitucionais, ou seja, oposições ao absolutismo. É justamente na produção desses impressos que percebemos a importância das tipografias pernambucanas como suporte para a circulação de ideias via palavra impressa.

O movimento insurrecional de 1817 sofreu grande repressão e muitos de seus participantes ficaram presos até o ano de 1821, ao passo que alguns deles foram responsáveis pelos periódicos que circularam na província no primeiro quartel do século XIX. Dessa forma, a atividade tipográfica inexistiu na província por cerca de quatro anos. A partir do ano de 1821, começaram a surgir os primeiros periódicos da província, sendo o primeiro deles o Aurora Pernambucana, conforme percebido no Quadro 1. 
Quadro 1 - Periódicos separados em vertentes por suas características políticas ${ }^{5}$

\begin{tabular}{|c|c|c|c|}
\hline Tendência política & Periódicos & Redatores & Período de publicação \\
\hline $\begin{array}{l}\text { 1- Apoio às Cortes } \\
\text { instauradas em Lisboa após } \\
\text { a Revolução do Porto e } \\
\text { propagação de suas medidas } \\
\text { sem debate. Circularam } \\
\text { antes da instauração da } \\
\text { Junta Provisória na } \\
\text { província. }\end{array}$ & $\begin{array}{l}\text { Aurora Pernambucana } \\
\text { O Relator Verdadeiro }\end{array}$ & $\begin{array}{l}\text { Rodrigo da Fonseca } \\
\text { Magalhães } \\
\text { Francisco Ferreira Barreto }\end{array}$ & $\begin{array}{l}\text { Março a setembro de } 1821 \\
\text { Dezembro de } 1821 \text { a maio } \\
\text { de } 1822\end{array}$ \\
\hline $\begin{array}{l}\text { 2- Transição entre o apoio e } \\
\text { o questionamento às } \\
\text { medidas tomadas pelas } \\
\text { Cortes de Lisboa. }\end{array}$ & Segarrega & $\begin{array}{l}\text { Felipe Mena Calado da } \\
\text { Fonseca }\end{array}$ & $\begin{array}{lccc}\text { Dezembro } & \text { de } & 1821 & \text { a } \\
\text { outubro de } 1822 & & \end{array}$ \\
\hline $\begin{array}{l}\text { 3- Questionamento das } \\
\text { medidas tomadas pelas } \\
\text { Cortes de Lisboa e proposta } \\
\text { de independência e } \\
\text { instauração de uma } \\
\text { Assembleia Constituinte no } \\
\text { Brasil. }\end{array}$ & $\begin{array}{l}\text { O Maribondo } \\
\text { Conciliador Nacional }\end{array}$ & $\begin{array}{l}\text { Padre José Marinho Falcão } \\
\text { Padilha } \\
\text { Frei Miguel do Sacramento } \\
\text { Lopes Gama }\end{array}$ & $\begin{array}{l}\text { Julho a outubro de } 1822 \\
\text { Julho de } 1822 \text { a outubro de } \\
1823\end{array}$ \\
\hline $\begin{array}{l}\text { 4- Crítica acentuada aos } \\
\text { ministros e, com ressalvas, } \\
\text { preservação da imagem da } \\
\text { monarquia brasileira. }\end{array}$ & $\begin{array}{l}\text { Escudo da Liberdade do } \\
\text { Brazil }\end{array}$ & $\begin{array}{l}\text { Padre Francisco Agostinho } \\
\text { Gomes e Capitão João } \\
\text { Mendes Viana } \\
\text { Cipriano José Barata de } \\
\text { Almeida }\end{array}$ & $\begin{array}{l}\text { Abril de } 1823 \text { a março de } \\
1824\end{array}$ \\
\hline $\begin{array}{lr}\text { 5- } & \text { Questionamentos } \\
\text { direcionados } & \text { mais } \\
\text { diretamente ao Imperador e } \\
\text { à monarquia. Desejo de } \\
\text { ruptura com o governo } \\
\text { instaurado no Rio de Janeiro }\end{array}$ & $\begin{array}{l}\text { O Typhis Pernambucano } \\
\text { O Liberal } \\
\text { Sentinela da Liberdade }\end{array}$ & $\begin{array}{l}\text { Frei Joaquim do Amor } \\
\text { Divino Caneca } \\
\text { Padre João Batista da } \\
\text { Fonseca } \\
\text { Cipriano José Barata de } \\
\text { Almeida }\end{array}$ & $\begin{array}{l}\text { Dezembro de } 1823 \text { a agosto } \\
\text { de } 1824 \\
\text { Fevereiro a março de } 1824 \\
\text { Abril de } 1823 \text { a março de } \\
1824\end{array}$ \\
\hline
\end{tabular}

Em Pernambuco, o contexto político permanecia agitado após a deposição da Junta de Gervásio Pires, a qual possuía um caráter político de oposição ao projeto unitário encabeçado pelos Andradas e se estendeu entre outubro de 1821 e setembro de $1822^{6}$. Após sua 
dissolução, o poder político foi exercido, entre setembro de 1822 e dezembro de 1823, por um grupo denominado "matutos", sendo formado por proprietários rurais, sem compromisso com o gervarismo ou com o unitarismo ${ }^{7}$ e uma das primeiras medidas da nova Junta foi a nomeação dos deputados que representariam a província na Assembleia do Brasil. ${ }^{8}$

Não se pode esquecer que entre os anos de 1823 e 1824 fatos importantes ocorreram e serviram de alimento para grande parte da cultura impressa que surgia em Pernambuco até o momento da Confederação do Equador. A criação e dissolução da Soberana Assembleia Constituinte e a imposição de um novo projeto constitucional, assim como a soberania da cidade do Rio de Janeiro em relação às demais províncias e a criação do Poder Moderador, foram temas constantemente debatidos nos periódicos impressos nas tipografias que pretendese analisar.

Ressalta-se, mais uma vez, que no período abrangido por este artigo, Pernambuco desenvolvia uma cultura impressa ainda em seu processo embrionário, mas que atuou de forma decisiva em um momento politicamente agitado da história do Brasil. Porém, salientase que a produção de material impresso já era comum em Portugal e outras províncias da América portuguesa, como Rio de Janeiro e Bahia, por exemplo. As relações existentes entre os periódicos que surgiram em Pernambuco e impressos de outras regiões da América portuguesa mostram a existência de pessoas vinculadas por grupos e redes de sociabilidades, de acordo com seus pressupostos político-ideológicos. Seus redatores buscavam propagar os ideais que se aproximavam do conceito que veio a ser chamado modernidade, processo que dependia de um aparato tipográfico, constituído de forma dinâmica naquele contexto.

Percebe-se, dessa maneira, que a cultura impressa que tomava forma em Pernambuco entre os anos de 1817 e 1824, principalmente nos últimos três anos, buscava desempenhar um papel que ia além de trazer informações. No material produzido pelas tipografias pernambucanas existem debates acerca dos acontecimentos políticos de seu tempo e expunha a opinião de diversas pessoas que, por meios das correspondências publicadas nos impressos, podiam se inserir em um universo jamais pensado durante o Antigo Regime. O papel da imprensa como um dos aspectos constitutivos da nação recém-independente e também como um elemento formador de opinião nos espaços públicos teve destaque em todo esse processo. ${ }^{9}$ Os espaços púbicos eram justamente os locais onde a opinião pública se formou. Este, que segundo François-Xavier Guerra, foi o elemento chave da constituição e propagação da política moderna. ${ }^{10}$

Para a compreensão do funcionamento das tipografias instaladas na cidade do Recife no primeiro quartel do século XIX, se faz necessário tomar conhecimento sobre quem eram 
seus tipógrafos, ou seja, quem eram as pessoas responsáveis por montar e administrar as tipografias. Sendo assim, aspectos das mentalidades desses personagens são pertinentes para o estudo da cultura impressa que surgia em Pernambuco. Vale lembrar que os tipógrafos eram pessoas ligadas aos redatores dos impressos, tendo algumas vezes os próprios dirigentes das tipografias assumido a redação de periódicos, conforme será mostrado adiante.

Dessa forma, procurou-se relacionar o fato de que havia aspectos do modelo posteriormente denominado modernidade política que estavam na ordem do dia para os impressores e redatores, mas a viabilização dessas ideias dependia das condições materiais de produção (como por exemplo, tipografias mais dinâmicas e modernas). É importante destacarmos que, mesmo as condições de produção do material sendo ainda bastante embrionárias, e contando com poucas pessoas que possuíssem prática na execução da atividade tipográfica, foi crescente o número de periódicos na província entre os anos de 1821 e 1824, conforme mostra o Quadro 1.

No decorrer dos acontecimentos que fertilizavam os debates e opiniões, as pessoas que possuíam determinado alinhamento político certamente se aproximavam e isso é perceptível quando se estuda a biografia dos autores e tipógrafos dos impressos, o que ocasionou o surgimento de vertentes político-ideológicas. Diversos personagens, em sua maioria ilustrados e, no caso dos redatores, vinculados à Igreja, foram responsáveis por dar dinâmica aos acontecimentos políticos. Das tipografias do Recife surgidas até 1824 inúmeros periódicos, panfletos e diários oficiais foram impressos contendo notícias que expunham determinados pontos de vistas muitas vezes inflamados pelo calor dos acontecimentos.

É pertinente não esquecer que a atividade tipográfica se tratava de um investimento financeiro, ou seja, não eram apenas os pressupostos político-ideológicos que ditavam seu funcionamento. $\mathrm{O}$ investimento em materiais e pessoas para o trabalho necessitava de lucros que viriam com a venda dos impressos e com isso muitos redatores chamavam debates para “acalorar” os números de seus periódicos e, consequentemente, aumentar o número de vendas. $\mathrm{O}$ fracasso nesse quesito poderia significar o término da publicação e prejuízo para o tipógrafo.

\section{Tipografias e Tipógrafos}

A primeira tipografia instaurada na província de Pernambuco nesse momento histórico pertenceu ao comerciante Ricardo Fernandes Castanho que, seguindo o exemplo do baiano Manoel da Silva Serva, mandou vir da Inglaterra "uma imprensa cujo material já se achava no 
Recife em fins de 1815, quando o seu proprietário solicitou do governo real a licença para dela fazer uso". ${ }^{11}$ Após o pedido feito ao governador Caetano Pinto de Miranda, que passou pela autoridade do ministro Marquês de Aguiar, foi concedida a licença para o funcionamento da tipografia:

\begin{abstract}
Sendo pois a tipografia uma das mais úteis invenções, e a que mais contribuiu para alimentar e propagar os conhecimentos humanos, parece-me que o seu uso se deve introduzir em Pernambuco, concedendo-se a Ricardo Fernandes Castanho, a quem agora chegou uma imprensa da Inglaterra, a licença que pede no requerimento incluso, o qual V. Exe. Me dirijo com o Aviso Régio de 29 de Março do ano passado pondo-se aqui em prática o mesmo plano de licença, revisão e censura que se acha estabelecido na Bahia. ${ }^{12}$
\end{abstract}

No entanto, devido à ausência de pessoal preparado para fazer funcionar a tipografia “a oficina ficou depositada nos armazéns do comerciante até estourar a revolução de 1817”. 13 Quando o movimento revolucionário eclodiu, viu-se a necessidade de criação de um meio de propagação dos ideais do governo provisório, e foi então que a tipografia, que dois anos antes havia sido comprada por Fernandes Castanho, veio a ser utilizada.

Testemunha ocular dos sucessos, o francês L. F. de Tollenare refere que, em palestra com o malogrado patriota, lembrara a conveniência de criação de uma gazeta destinada a doutrinar o povo, que nada compreendia dos intuitos da mudança de regime político. ${ }^{14}$

O viajante e cronista francês Louis F. Tollenare, tendo como fonte as informações de Antônio Joaquim de Mello, ${ }^{15}$ ainda nos fornece informações importantes sobre as pessoas que estavam ligadas à instalação da tipografia do governo de 1817:

Dois frades, um inglês e um marinheiro francês foram os primeiros tipógrafos improvisados: entretanto, Antonio Joaquim de Mello, cuja veracidade não pode ser contestada, assevera que a imprensa foi montada pelo inglês James Pinches. ${ }^{16}$

O inglês James Pinches foi um dos pioneiros na instalação da tipografia em Pernambuco e esteve presente inclusive na fundação da Tipografia Cavalcante e Companhia, conforme veremos adiante. Segundo o relato de Joaquim de Mello, "por alguns dias [James Pinches] a administrou, sendo sucedido por Joaquim Bernardo Fróes, natural de Pernambuco, assim como o eram todos os outros paisanos trabalhadores, ou compositores". ${ }^{17}$

Na obra de Pereira da Costa, no que diz respeito à organização e o funcionamento da tipografia nesse primeiro momento, tem-se a seguinte informação: 
A direção literária dos trabalhos da imprensa, como consta do depoimento do Dr. Antonio Carlos Ribeiro de Andrada Machado e Silva, como implicado na revolução coube com acerto ao Padre João Ribeiro Pessoa: o serviço artístico, porém, foi confiado ao cidadão inglês James Pinches, que destarte iniciou em Pernambuco a arte tipográfica, pelo que deve ser considerado como o primeiro dos preceptores e o seu nome conhecido e venerado por todos dos tipógrafos. ${ }^{18}$

A tipografia inicialmente recebeu o nome de Oficina Tipográfica da $2^{\mathrm{a}}$ Restauração de Pernambuco, mas, segundo Tollenare, o padre João Ribeiro ${ }^{19}$ escrevera para James Pinches: "Patriota Pinches, tende a bondade de pôr no fim de nossos papéis: Na Oficina Tipográfica da República de Pernambuco, segunda vez restaurada". ${ }^{20}$

Após o surgimento de Preciso $^{21}$, seguiram-se algumas proclamações publicadas pela tipografia. No entanto, devido à repressão feita pelo governo central ao movimento republicano, em 15 de setembro de 1817, foi baixado um aviso firmado pelo ministro Thomaz Antonio de Villa Nova Portugal que determinava que a tipografia encerrasse suas atividades:

Tomado o governo em consideração o infame abuso que se fez da oficina tipográfica em Pernambuco, houve por bem cassar a licença que concedeu por Aviso de 9 de Novembro de 1816 para o seu estabelecimento, - ordenado destarte ao governador que a mandasse fechar e remetesse seu material para o Rio de Janeiro. ${ }^{22}$

Foi quando Luiz do Rego, então presidente da província, expediu, a 4 de novembro, uma portaria ao tenente coronel inspetor do Trem, depois Arsenal de Guerra, que mandasse tomar conta da imprensa. No entanto, a "tipografia dos rebeldes" foi enviada para a Corte apenas em $1819 .^{23}$

Todavia, nem todo o material da tipografia foi enviado ao Rio de Janeiro. Alguns tipos haviam permanecido em Pernambuco e, após o movimento liberal de 1820 ocorrido em Portugal, o governador da província, Luiz do Rego, se valeu do material que havia restado e, construindo um prelo de madeira, rebatizou a tipografia de Oficina do Trem de Pernambuco, publicou algumas proclamações e papéis avulsos até que, chegou a publicar, em 27 de março de 1821, o número inicial do Aurora Pernambucana, primeiro periódico publicado em Pernambuco. A tipografia ficou com seus prelos inativos durante o movimento de resistência ao presidente da província e principal responsável pelas publicações, Luiz do Rego, até voltar à atividade com o surgimento da junta provisória, quando Gervásio Pires Ferreira foi eleito presidente e nesse momento ela ganhou o nome de Oficina do Trem Nacional de Pernambuco. $^{24}$ 
Contudo, no ano de 1822, foi decretado que se estabelecesse uma tipografia na província para publicações oficiais referentes às medidas tomadas pelo governo central e pela Junta de Governo. Naquela ocasião, com todo o aparato da Oficina do Trem Nacional de Pernambuco criou-se, por meio de um decreto direcionado para a Junta de Governo, a Tipografia Nacional onde foram investidas grandes somas em dinheiro para se trazer prelos da Inglaterra e montar uma tipografia moderna para os padrões da época, além de buscar profissionais qualificados e devidamente remunerados para o serviço. Porém, deve-se levar em consideração que a chegada de um aparato tipográfico arrojado para o período mostra que aspectos do que viria a se concretizar como modernidade estava presente em Pernambuco, e não apenas na Europa, local de origem desse material. Conforme apresentado por Pereira da Costa:

Depois da partida de Luiz do Rego, e serenados os ânimos populares, resolveu a junta do governo provisório estabelecer uma tipografia regular, e para isso encarregou a casa comercial de Antonio da Silva \& C. de fazer a encomenda para Londres de todo o material necessário, cuja fatura importou em 3:185\$705;

Em 1822 mandou o governo vir novos tipos por intermédio da mesma casa comercial, visto ser insuficiente as fontes que vieram com a tipografia, importando a fatura em 2:292\$060.

Montada a oficina com sofrível material em que se notava-se um elegante prelo de ferro adornado com uma águia do mesmo metal, começou a funcionar em $1822 \mathrm{sob}$ a denominação de Tipografia Nacional, dirigida por um administrador de nomeação do governo, com ordenado de $400 \$ 000$ anuais, tendo como auxiliar um escriturário com 160\$000, lugares esses que foram postos em concurso pelo edital de 22 de junho do mesmo ano. ${ }^{25}$

É importante destacar que, além do dirigente, a Tipografia Nacional contava com um auxiliar, também com algum conhecimento na arte tipográfica e assalariado, mostrando a busca por melhorias na qualidade dos impressos, além do flagrante aumento quantitativo do número de gazetas, conforme mostrado anteriormente.

Depois de algumas publicações de periódicos como Segarrega, Gazeta Extraordinária do Governo, Conciliador Nacional e O Maribondo, a Tipografia Nacional foi adquirida por um grupo de pessoas de grande importância para a construção desse momento da cultura impressa pernambucana. Um deles era Manoel do Rego Clemente Cavalcante, importante tipógrafo e também redator de impressos. O outro era Felipe Mena Callado da Fonseca, português que havia chegado ao Recife com apenas nove anos de idade e que morreu aos 87 
anos no dia 30 de agosto de $1878 .^{26}$ Por fim, James Pinches, um inglês que, conforme visto, foi um dos pioneiros na arte tipográfica em Pernambuco, tendo participado da administração da tipografia utilizada pelo governo revolucionário de 1817.

Quadro 2 - As Tipografias e os periódicos que produziram ${ }^{27}$

\begin{tabular}{|l|l|}
\hline \multicolumn{1}{|c|}{ Nome da tipografia } & \multicolumn{1}{|c|}{ Periódicos produzidos } \\
\hline Oficina do Trem Nacional de Pernambuco & $\begin{array}{l}\text { Aurora Pernambucana } \\
\text { Segarrega } \\
\text { Relator Verdadeiro }\end{array}$ \\
\hline Tipografia Nacional & $\begin{array}{l}\text { Segarrega } \\
\text { Relator Verdadeiro } \\
\text { O Maribondo } \\
\text { O Conciliador Nacional }\end{array}$ \\
\hline Tipografia Cavalcante e Companhia & $\begin{array}{l}\text { Sentinela da Liberdade } \\
\text { Escudo da Liberdade do Brazil } \\
\text { O Conciliador Nacional } \\
\text { O Maribondo } \\
\text { Tipografia de Miranda e Companhia }\end{array}$ \\
& $\begin{array}{l}\text { Segarrega } \\
\text { O Liberal } \\
\text { Sentinela da Liberdade }\end{array}$ \\
\hline
\end{tabular}

Ao observar os Quadros 1 e 2 é possível perceber a relação entre os grupos de periódicos e as tipografias. Por exemplo, a Tipografia de Miranda e Companhia publicou os dois periódicos pertencentes à vertente mais radical em relação às medidas tomadas pelo governo do Rio de Janeiro, ou seja, O Typhis Pernambucano, o impresso O Liberal e números posteriores do Sentinela da Liberdade. Também é notável que a Cavalcante e Companhia tenha sido responsável pela produção dos primeiros números do Sentinela da Liberdade e do Escudo da Liberdade do Brazil na íntegra, pertencentes à uma vertente ideológica que antecedeu as críticas mais profundas ao Rio de Janeiro.

Após se tornar uma empresa particular, a antiga Tipografia Nacional passou então a possuir o nome de Tipografia de Cavalcante e Companhia. Entre esses personagens, Manoel Cavalcante foi o mais importante no andamento da oficina tipográfica. Havia regressado pouco antes de Portugal e instalado uma tipografia na Rua Direita, $n^{\circ} 256$. Após o governo anunciar a venda de todo o material que havia restado da Tipografia Nacional, Cavalcante, 
que também fora redator da Aurora Pernambucana, do número 23 em diante, ${ }^{28}$ adquiriu, junto com seus dois sócios, o material. Funcionando com três prelos, a nova tipografia publicou números dos seguintes periódicos: O Conciliador Nacional, Segarrega, Gazeta Pernambucana (integralmente), Gazeta do Governo Temporário, Gazeta do Governo Provisório, Diário da Junta do Governo de Pernambuco, Sentinela Da Liberdade e Escudo da Liberdade do Brazil.

No entanto, o número 13 do Typhis Pernambucano, publicado no dia $1^{\circ}$ de abril de 1824, mostra que as relações de Manoel Cavalcante não eram das melhores com todos os jornalistas de seu período. Nesse caso, Frei Caneca ${ }^{29}$ fez duras críticas ao sócio proprietário da Cavalcante e Cia, afirmando que ele tirava proveito dos movimentos dos quais havia participado, inclusive o levante de 1817, acusando-o de agir falsamente e de acordo com seus interesses, além de possuir dívidas pessoais e referentes à compra da própria tipografia, que nunca foram pagas. ${ }^{30} \mathrm{O}$ Typhis, que afirmava nesse número o envolvimento de Cavalcante com uma suposta sedição encabeçada pelos Andradas no Rio de Janeiro, questionava:

Quais são os fundos e capitais do famoso Manoel do Rego Clemente Cavalcante? Com quantas assinaturas tem ele entrado para o Banco? Quais são os seus estabelecimentos e propriedades, além das gírias, espertezas e velhacarias em que é um gênio sublime? ? $^{31}$

O periódico inflamado dirigido por Frei Caneca estava comprometido com a difamação de Manoel Clemente Cavalcante, que além de defender a nomeação do morgado ${ }^{32}$ para presidente da província, era proprietário de uma tipografia que dividia o papel de centro propagador de notícias com aquela empresa que publicava o periódico de Caneca, a Miranda e Cia. Talvez essa situação tenha gerado uma rivalidade entre ambos, o que pode ser notado devido ao caráter pessoal das críticas desferidas pelo padre jornalista ao tipógrafo. Esse posicionamento parece atestar a existência de vínculos ideológicos e, até mesmo, comerciais, entre os redatores e produtores do material.

Mais adiante, no mesmo número, o Thyphis Pernambucano prossegue com o tom de discurso crítico referente à Cavalcante, alegando que: "Comprando ao estado, por quatro contos de réis a tipografia fiada, a tem desfrutado três anos, sem ainda ter feito um só pagamento $[\ldots]$ ]"33 e, prosseguindo com a crítica, destaca: "Pedindo, em 1821, a certa pessoa desta praça, a quantia de duzentos mil réis por poucos dias, ainda até hoje sem dinheiro, nem, ao menos, uma pequena satisfação. Que herói! Que malandrinho! Quem se pode pôr a barba com ele". ${ }^{34}$ De forma bastante contundente, O Typhis fez outras acusações ao famoso 
tipógrafo, proprietário da Cavalcante e Cia: "Manoel Clemente é aquele traidor que, de mãos dadas com o célebre padre Soledade e outros, desligou o Imperador do juramento prévio à Constituição que o Brasil fizesse [...]".35

Ao que parece, as acusações de Frei Caneca podem ter surtido algum efeito, pois em 13 de junho de 1824, foi baixada uma portaria ordenando James Pinches, administrador da Cavalcante e Cia, a entregar ao inspetor do Trem todo o material da tipografia, que novamente se tornaria um instrumento governamental e reassumiria o nome de Tipografia Nacional. Pinches foi convidado para trabalhar nessa nova fase da empresa tipográfica, sendo o tipógrafo José Miranda Falcão escolhido para assumir a direção, auxiliado por um escrivão e um contínuo. ${ }^{36}$ No entanto, esse novo momento da tipografia durou pouco tempo, o que foi suficiente para imprimir os dois últimos números do Typhis Pernambucano ${ }^{37}$ e os números 1 ao 4 do Registro Oficial do Governo de Pernambuco. Após a repressão da Confederação do Equador, o general Francisco de Lima e Silva delegou a responsabilidade da tipografia para o Padre Lopes Gama, que publicou apenas alguns números do Conciliador Nacional, periódico que ele dirigia e números do Diário do Governo de Pernambuco ${ }^{38}$ Contudo, conforme podese ver na passagem abaixo, a vida da Tipografia Nacional foi efêmera:

Não deu, porém, a Imprensa Nacional o resultado que se esperava, a sua receita não compensava a despesa do custeio, e destarte resolveu o governo extingui-la ordenando por portaria de 6 de agosto de 1825 que todo seu material fosse recolhido ao Trem Militar “por ter caído em desuso, por falta de escritores, que por via daquele prelo instruíam o público com seus escritos. Sem mesmo ter continuado os dois periódicos que até então se imprimiam, e não permitir o estado dos cofres nacionais que se continuasse a fazer a despesa de $720 \$$ com empregados que ali se achavam sem fazer nada. ${ }^{39}$

O excerto acima é interessante por levantar questões salutares, como os investimentos feitos na tipografia e as expectativas de consumo dos impressos. Mesmo com o sensível aumento do número de periódicos e o desenvolvimento de uma cultura de leitura na região, a manutenção de uma empresa tipográfica não era das tarefas mais fáceis.

O número de periódicos aumentava com o advento do novo momento político vivido na América Ibérica e essas características, entre outras, são inerentes ao conceito de modernidade, que trouxe novas formas de sociabilidade e de transmissão de conhecimento, proporcionando a novos agentes sociais a inserção em debates acerca da política e dos rumos que a nação deveria tomar. No caso de Pernambuco, não foi diferente e a primeira tipografia surgida nesse momento na província, sobre a qual tratamos nas linhas anteriores, parece não 
ter dado conta, ou não ter tido interesse em outras publicações. Sendo assim, houve uma concorrente nessa atividade, a Miranda e Cia., que parece ter aproveitado o momento político e, de certa forma cultural, em que estava inserida a província para lançar mão de um aparato tipográfico. Nesse caso, a Tipografia Miranda e Cia imprimiu alguns periódicos de posturas mais radicais frente o governo do Rio de Janeiro. Ao final do ano de 1823, Antônio José Miranda Falcão deu início às atividades de uma pequena oficina tipográfica no bairro da Boa Vista. A empresa teve o nome de Tipografia de Miranda e Cia e publicou os seguintes periódicos: O Typhis Pernambucano, O Liberal, Sentinela da Liberdade (2 ${ }^{\mathrm{a}}$ fase), Argos Pernambucano e Desengano aos Brasileiros, contribuindo, dessa maneira, para a atividade de importantes folhas impressas.

Percebe-se na figura de Miranda Falcão características interessantes: ao mesmo tempo que deveria voltar seus esforços para a obtenção de lucro com seu empreendimento tipográfico, parece ter optado, conforme vimos anteriormente, pela impressão de papéis mais radicais. Impressos como o Sentinela da Liberdade, de Cipriano Barata, mesmo sendo ácidos em suas críticas e perseguidos pela censura, significavam garantia de vendas, pois os números tinham inúmeras reedições e eram lidos e debatidos pelas ruas do Recife, além de serem consumidos em outras províncias, como Bahia, Paraíba e Rio de Janeiro, por exemplo. ${ }^{40}$ Ao que parece, o proprietário da Miranda Falcão pertencia ao mesmo grupo de pessoas que estavam ligadas por ideias e acontecimentos nos movimentados dias tempestuosos que enfrentou a nau pernambucana, ${ }^{41}$ esse grupo era formado por pessoas como o padre João Batista da Fonseca redator de $O$ Liberal, o padre Venâncio Henriques de Resende, presente em vários debates impressos e redator de impressos oficiais, Frei Caneca, redator do Typhis Pernambucano ${ }^{42}$ e o tipógrafo que publicava seus impressos, Miranda Falcão.

O proprietário da Tipografia de Miranda e Companhia possuía experiência como tipógrafo, pois havia trabalhado na Oficina do Trem, um antigo arsenal de guerra que deu lugar à tipografia. Nesse mesmo local, Miranda havia sido professor na escola do Arsenal e parece ter aprendido o ofício de impressor com James Pinches. ${ }^{43}$ Além de exercer a atividade de professor, Miranda também havia sido padre, ${ }^{44}$ o que, de certa forma, o identifica com grande número dos redatores e editores desse momento da imprensa pernambucana. Além do que, o proprietário da Miranda e Cia também havia ajudado Frei Caneca na redação do Thyphis Pernambucano, comprovando seu vínculo pessoal e alinhamento ideológico com Caneca, fato que contribui para esclarecer os motivos que o levaram a investir tantas linhas realizando críticas a um dos proprietários da tipografia que já estava consolidada em Recife, Manoel Cavalcante, da Cavalcante e Cia. 
Assim como ocorrera com diversas pessoas envolvidas na Confederação do Equador, movimento político que abalou as províncias do Norte do Império, o proprietário da Miranda $e$ Cia foi condenado à prisão, mas, ao que tudo indica, não permaneceu muito tempo no cárcere, pois negociando sua liberdade com o poder público, adquiriu o material que havia pertencido à então extinta Tipografia Nacional, e posteriormente, em 7 de novembro de 1825, publicou aquele que se tornou o periódico com maior tempo de circulação no continente americano, o Diário Pernambucano. ${ }^{45}$

Ainda há uma questão muito importante que deve ser colocada sob um foco analítico que se trata das tipografias como locais de venda e consumo dos impressos. A passagem de $O$ Liberal, a seguir, mostra a Tipografia de Miranda e Companhia como local de compra do material. Podemos deduzir que as pessoas ligadas à produção dos periódicos e ao seu consumo, ou seja, redatores, leitores e anunciantes, se encontravam nas tipografias, tonando esses locais núcleos propagadores de notícias e de opiniões que poderiam circular nos próximos números, ou poderiam já ter circulado nos impressos em números anteriores.

Quem quiser assinar a Sentinela da Liberdade, e o Liberal dirija-se na Boa Vista à Tipografia de Miranda, em S. Antonio à loja de José Gonçalves de Faria na rua do Rosário, ao pé da quina do Cabugá, ou na imediata de Bernardino de tal; e no Recife na Casa do Comércio. A assinatura é de uma pataca mensal por ambos os periódicos, e todos os suplementos, e papéis avulsos do Redator serão dados aos assinantes de graça: a assinatura será paga adiantada, e os periódicos serão procurados pelos assinantes nos lugares mencionados. Sairá o Liberal na terça-feira, e a Sentinela no Sábado, impreterivelmente. ${ }^{46}$

É significativo a existência do esforço para a distribuição dos impressos: no anúncio acima, por exemplo, os periódicos Sentinela da Liberdade e $O$ Liberal lançam o que anacronicamente poderíamos chamar de "promoção", tendo seus redatores forte vínculo com o proprietário da Miranda e Cia, conforme vista anteriormente. Dessa forma, o ciclo de produção do material impresso ${ }^{47}$, estava posto e dialogando de forma intensa e bastante significativa.

Todos esses personagens faziam parte de uma ampla rede que envolvia aqueles que escreviam o texto, ou seja, os redatores e dirigentes dos periódicos, e aqueles que eram responsáveis pela produção do material, ou seja, os tipógrafos. Aos donos das tipografias coube a tarefa de realizar o investimento financeiro e de se arriscar em uma atividade ainda pouco explorada na província pernambucana; aos redatores coube a reflexão sobre os acontecimentos políticos presentes em todas as partes do mundo, das quais pudessem trazer 
informações e a realização da escrita do texto em si, mesclando as correspondências com suas próprias análises pessoais acerca desses acontecimentos. ${ }^{48} \mathrm{Em}$ suas folhas ainda deveriam ter espaço trechos de periódicos produzidos na América e na Europa, além de transcrições de documentos oficiais e anúncios. Dessa forma, percebemos que havia o controle do discurso por parte dos responsáveis pela produção dos textos, que, além de exporem suas análises sobre diversas questões, na grande maioria das vezes, se mantinham no anonimato.

\section{Notas}

${ }^{1}$ Sobre essas manifestações, ver: CABRAL, Flavio José Gomes. Vozes públicas: as ruas e os embates políticos em Pernambuco na crise do Antigo Regime português (1820-1821). In: SAECULUM, Revista de História. João Pessoa, jul/dez, 2005.

${ }^{2}$ RAMIRES, Mário Fernandes. Palavras impressas em tempos de luta: periódicos pernambucanos e os debates políticos ocorridos entre 1821 e 1824. Dissertação (Mestrado em História Cultural) - Escola de Filosofia, Letras e Ciências Humanas, Universidade Federal de São Paulo, São Paulo, 2014, pp. 16-76 e 120-160.

${ }^{3}$ No ano de 1817, a província de Pernambuco realizou uma revolução e se proclamou uma República, separada do Império do Brasil. Entre as causas da revolta pode-se destacar a estiagem do ano de 1816 e a carestia dos alimentos. É interessante notar que o movimento republicano contou com um governo provisório heterogêneo e deu início às atividades tipográficas em Pernambuco no século XIX. Sobre esse acontecimento ver MOTA, Carlos Guilherme. Nordeste, 1817. São Paulo: Editora da Universidade de São Paulo/Editora Perspectiva, 1972.

${ }^{4}$ GUERRA, François-Xavier. Modernidad e independencia: ensayos sobre las revoluciones hispánicas.

Madrid: MAPFRE, 1992.

${ }^{5}$ Fonte: todas as informações acerca da localização das fontes consultadas estão no item "Fontes e documentos", na página 20 deste artigo.

${ }^{6}$ BERNARDES, Denis Antônio de Mendonça, O patriotismo constitucional: Pernambuco, 1820-1822. São Paulo; Recife: Hucitec/Fapesp; Editora da UFPE, 2006, pp. 315-354.

${ }^{7}$ Os gervaristas eram aqueles que, assim como o governador Gervásio Pires, tinham certa desconfiança em se aliar plenamente ao processo de independência encabeçado no Rio de Janeiro pelos Andradas, grupo político ao qual pertencia Dom Pedro I. No caso dos unitários, se tratavam justamente de um grupo desejoso de aderir ao projeto do Rio de Janeiro. Sobre esses grupos, ver MELLO, Evaldo Cabral de. A outra independência: o federalismo pernambucano de 1817 a 1824. São Paulo: Editora 34, 2004.

${ }^{8}$ Ibid., pp. 113-162.

${ }^{9}$ MOREL Marco \& BARROS, Marina Monteiro de. Palavra, imagem e poder: o surgimento da imprensa no Brasil do século XIX. Rio de Janeiro, DP \& A, 2003.

${ }^{10}$ GUERRA, op. cit., p.p 275-318.

${ }^{11}$ CARVALHO, Alfredo de. Annaes da imprensa periódica pernambucana de 1821-1908. Recife: Tipografia do Jornal do Recife, 1908, p. 30.

${ }^{12}$ COSTA, Francisco Augusto Pereira da. Estabelecimento e desenvolvimento da imprensa em Pernambuco. Revista do Instituto Arqueológico, Histórico e Geográfico Pernambucano, Recife, n. 39, p. 28, 1891.

${ }_{13}^{13}$ MORAES, Rubem Borba de. Livros e bibliotecas no Brasil colonial. 2006. Brasília: Briquet de Lemos, 2006, p. 172.

${ }^{14}$ TOLLENARE, L.F. Notas dominicais, Recife, 1905 apud CARVALHO. op. cit., p. 33.

${ }^{15}$ Membro da Igreja e ilustrado envolvido nos acontecimentos de 1817, foi eleito vereador da Câmara de Recife em 1823, mas não assumiu por estar envolvido na Confederação do Equador. Antonio Joaquim de Mello ainda publicou o periódico $O$ Caetés nesse mesmo ano. COSTA, Pereira da. Dicionário biográfico de pernambucanos célebres. Recife: Tipografia Universal, 1882, p. 103.

${ }^{16}$ MELLO, J. apud CARVALHO. op. cit., p. 33.

17 Ibidem.

${ }^{18}$ COSTA, op. cit., p. 30. 
19 Ilustrado pernambucano e participante da Insurreição de 1817, confeccionou a bandeira da República instaurada e Pernambuco. A respeito deste personagem, ver ALCÂNTARA, Laurita Maria de. Paulista: algumas contribuições para a sua história. Paulista: Editora Claranto, 2002.

${ }^{20}$ TOLLENARE, L.F., apud MORAES, op. cit., p. 172.

${ }^{21}$ A produção de material impresso na província de Pernambuco durante o século XIX teve seu início em 1817 com a publicação do folheto intitulado Preciso, escrito por José Luis Mendonça. Abordava, de maneira resumida, o processo da insurreição ocorrida em março daquele ano, apontando suas causas e esclarecendo como havia sido realizada a composição do governo provisório e repressão realizada pelo governo central. O título completo do impresso era Preciso dos sucessos, que tiverão lugar em Pernambuco, desde a faustíssima e gloriozíssima revolução operada felismente na praça do Recife, aos seis do corrente mez de março, em que o generozo esforço de nossos bravos PATRIOTAS exterminou daquella parte do Brazil o monstro infernal da tirania real. Oficina tipográfica da $2^{\mathrm{a}}$ Restauração de Pernambuco, 10 de março de 1817.

${ }^{22}$ COSTA, op. cit., p. 31.

${ }^{23}$ Ibid., p. 32.

${ }^{24}$ Ibid., pp. 32-33.

${ }^{25}$ Ibid., p. 37.

${ }^{26}$ NASCIMENTO, Luiz do. História da imprensa de Pernambuco (1821-1954). Recife: Editora da Universidade Federal de Pernambuco, 1969, p 24.

${ }^{27}$ Fonte: todas as informações acerca da localização das fontes consultadas estão no item "Fontes e documentos", na página 20 deste trabalho.

${ }^{28}$ O Typhis Pernambucano, Pernambuco, n. 13, 1 de abril de 1824. CHACON, Vamireh \& LEITE NETO, Leonardo (Orgs.), Brasília: Centro Gráfico do Senado Federal, 1984, p.128.

${ }^{29}$ Frei Joaquim do Amor Divino Caneca foi um religioso recifense muito importante nos acontecimentos políticos ocorridos no primeiro quartel do século XIX. Entre outras atividades, foi responsável pela publicação de $O$ Typhis Pernambucano, principal veículo de informação do movimento conhecido como Confederação do Equador, ocorrido em Pernambuco no ano de 1824 e MOREL, Marco. Frei Caneca: entre Marília e a pátria. Rio de Janeiro: FGV Editora, 2000.

${ }^{30}$ Ibidem.

${ }^{31}$ Ibidem.

${ }^{32}$ O colégio eleitoral de Pernambuco, reunido em 8 de janeiro de 1822, elegeu Manoel de Carvalho Paes de Andrade para governador da província, pois, conforme consta no número 7 de $O$ Typhis Pernambucano, o Imperador não havia nomeado ninguém para o cargo, apesar de haver boatos. Nesse caso, Dom Pedro I havia nomeado o morgado do Cabo, Francisco Paes Barreto, que assumiu o governo, compondo a Junta dos Matutos. Após a nomeação do morgado para presidente da província, houve mais efervescência no debate político, questionando se o Imperador não haveria recebido as reclamações da província acerca dessa nomeação. Ver MELLO, op cit., pp. 113-162.

${ }^{33}$ O Typhis Pernambucano. n.13. op. cit. CHACON \& LEITE, p. 131.

${ }^{34}$ Ibid., p. 132.

${ }^{35}$ Ibidem.

${ }^{36}$ COSTA, op. cit., pp. 38-39.

37 O Typhis Pernambucano, n. 28. op. cit., CHACON \& LEITE, op. cit., pp. 241. No entanto, CARVALHO afirma que foram impressos do 1 ao 27 na Tipografia de Miranda e Cia, o que deixaria margem apenas para o último número, o 28, ter sido impresso na Tipografia Nacional.

${ }^{38}$ COSTA, op. cit., p. 39.

${ }^{39}$ Ibidem.

${ }^{40}$ RAMIRES, op. cit., pp. 16-76

${ }^{41}$ Toma-se a liberdade de utilizar a relação metafórica de uma embarcação em perigo com a nação, atormentada pelos rumos perigosos que tomava. Essa relação não é difícil de ser encontrada nos periódicos pernambucanos do primeiro quartel do século XIX. Em O Typhis Pernambucano, por exemplo, existem passagens que fazem essa relação: "São passados quinze dias que trazemos, entre as mãos, o astrolábio para conhecermos a longitude e latitude dos negócios políticos do nosso Império, e não nos tem sido possível descobrir uma só estrela; tudo são carrancas, escuridões, nevoeiros; tudo são tempestades do Capricórnio. Está em conjunção a política com a astronomia”, Ver O Typhis Pernambucano, n. 3, 8 de janeiro de 1824: Pernambuco, Tipografia Miranda e Companhia, apud CHACON \& LEITE, op. cit., p 52. Nessa passagem é possível perceber diversas alusões feitas por Frei Caneca a instrumentos e técnicas de navegação, relacionando-os com os problemas que afetavam a política brasileira.

${ }^{42}$ Sobre a atuação desses personagens como redatores, bem como suas biografias, ver RAMIRES, op. cit., pp. 89-119. 


\footnotetext{
${ }^{43}$ HALLEWELL, Laurence. O Livro no Brasil: sua história. Edição Ilustrada, São Paulo: Edusp, 2005, pp. 187-188.

${ }^{44}$ Ibidem.

${ }^{45}$ CARVALHO, op. cit., p. 43.

${ }^{46}$ FONSECA, João Batista da. O Liberal. n. 19. Pernambuco: Tipografia de Cavalcante e Companhia, 13 de fevereiro de 1824. 4 páginas. Arquivo Público Estadual Jordão Emerenciano, Loc. MR - XIX L - $15^{a}$.

${ }^{47}$ CHARTIER, Roger. O mundo como representação. Estudos Avançados, v. 5, n. 11. São Paulo: Universidade de São Paulo, 1991.

${ }^{48}$ Para a relação entre os redatores e produtores do material impresso, de maneira geral, ver DARNTON, Robert. O Beijo de Lamourette:. mídia, cultura e revolução. São Paulo: Companhia das Letras, 1990; e, do mesmo autor, O que é a história do livro: revisitado. ArtCultura, INHIS-UFU, v. 10. n. 16. Tradução: Lilia Gonçalves Magalhães Tavolaro. Uberlândia, 2008.
}

\section{Referências Bibliográficas}

ALCÂNTARA, Laurita Maria de. Paulista. Algumas Contribuições para a sua História. Paulista: Editora Claranto, 2002.

BERNARDES, Denis Antônio de Mendonça. O patriotismo constitucional: Pernambuco, 1820-1822. São Paulo; Recife: Hucitec/Fapesp; Editora da UFPE, 2006.

BRAGANÇA, Aníbal \& ABRREU, Márcia (orgs.). Impresso no Brasil. Dois séculos de livros brasileiros. São Paulo: Editora Unesp, Ministério da Cultura. Fundação Biblioteca Nacional, 2008.

CABRAL, Flavio José Gomes. Vozes públicas: as ruas e os embates políticos em Pernambuco na crise do Antigo Regime português (1820-1821). In: SAECULUM, Revista de História. João Pessoa, jul/dez, 2005.

CARVALHO, Alfredo de. Annaes da Imprensa Periódica Pernambucana de 1821-1908. Recife: Tipografia do Jornal do Recife, 1908.

CHACON, Vamireh \& NETO, Leonardo Leite (orgs.). O Typhis Pernambucano. Frei Joaquim do Amor divino Caneca. Brasília: Centro Gráfico do Senado Federal, 1984.

CHARTIER, Roger. O mundo como representação. In: Estudos avançados, v. 5, no 11 . São Paulo: Universidade de São Paulo, 1991.

(org.) Práticas de leitura. Tradução: Cristiane Nascimento. $5^{\mathrm{a}}$ edição. São Paulo: Estação Liberdade, 2011.

COSTA, Francisco Augusto Pereira da. Dicionário biográfico de pernambucanos célebres. Recife: Tipografia Universal, 1882.

Estabelecimento e desenvolvimento da imprensa em Pernambuco. In: Revista do Instituto Arqueológico, Histórico e Geográfico Pernambucano, número 39. Recife: Typographia de F. P. Boultreau, 1891,

DARNTON, Robert. O Beijo de Lamourette. Mídia, cultura e revolução. São Paulo: Companhia das Letras, 1990 e, do mesmo autor, "O que é a história do livro. Revisitado". In: ArtCultura, INHIS-UFU, v. 10. Número 16. Tradução: Lilia Gonçalves Magalhães Tavolaro. Uberlândia, 2008.

GUERRA, François-Xavier; Modernidad e Independencia: ensayos sobre las revoluciones hispánicas. Madrid: MAPFRE, 1992.

HALLEWELL, Laurence. O Livro no Brasil. Sua história. Edição Ilustrada, $2^{\text {a }}$ Ed. São Paulo: Edusp, 2005. 
JANCSÓ, István (org.). Independência: História e Historiografia. São Paulo: Hucitec, Fapesp, 2005.

MOTA, Carlos Guilherme. Nordeste, 1817. São Paulo: Editora da Universidade de São Paulo, Editora Perspectiva, 1972.

MORAES, Rubem Borba de. Livros e bibliotecas no Brasil colonial. 2006. $2^{\text {a }}$ edição. Brasília: Bruiquet de Lemos, 2006.

MOREL Marco \& BARROS, Marina Monteiro de. Palavra, imagem e poder: o surgimento da imprensa no Brasil do século XIX. Rio de Janeiro, DP \& A, 2003.

MOREL, Marco. Frei Caneca. Entre Marília e a Pátria. Rio de Janeiro: FGV Editora, 2000.

MELLO, Evaldo Cabral de. A outra independência. O federalismo pernambucano de 1817 a 1824. São Paulo: Editora 34, 2004.

NASCIMENTO, Luiz do. História da Imprensa de Pernambuco (1821-1954). Recife: Editora da Universidade Federal de Pernambuco, 1969.

NEVES, Lúcia Maria Bastos P.; MOREL, Marco; FERREIRA, Tânia Maria Bessone da C. História e Imprensa. Representações culturais e práticas de poder. Rio de Janeiro: D P\&A - FAPERJ, 2006.

RAMIRES, Mário Fernandes: Palavras impressas em tempos de luta: periódicos pernambucanos e os debates políticos ocorridos entre 1821 e 1824. Dissertação (Mestrado em História Cultural). Escola de Filosofia, Letras e Ciências Humanas, Universidade Federal de São Paulo, 2014.

\section{Fontes e Documentos}

\section{AURORA PERNAMBUCANA}

Números 1, 3, 5, 6, 8, 15, 20, 21, 28 e 29. Pernambuco: Oficina do Trem Nacional, 1821. Números consultados parcialmente em NASCIMENTO, Luiz do. História da Imprensa de Pernambuco (1821-1954). Recife: Editora da Universidade Federal de Pernambuco, 1969.

DiÁRIO DA JUNTA DE GOVERNO, Nº 6 . Pernambuco: Tipografia de Cavalcante e Companhia, 1824. 4 páginas.

GAZETA PERNAMBUCANA, Pernambuco: Tipografia Cavalcante e Companhia, 1822. 4 páginas. Acervo digital da Biblioteca Brasiliana e Guita e José Mindlin da Universidade de São Paulo.

\section{RELATOR VERDADEIRO}

Todos os números extraídos do Acervo digital da Biblioteca Brasiliana e Guita e José Mindlin da Universidade de São Paulo.

Número 1. Pernambuco: Tipografia Nacional, 1821.

Número 2. Pernambuco: Oficina do Trem Nacional em Pernambuco, 1821.

Suplemento ao Número 2. Pernambuco: do Trem Nacional em Pernambuco, 1821.

Número 3. Pernambuco: Oficina do Trem Nacional em Pernambuco, 1822.

Número 4. Pernambuco: Oficina do Trem Nacional, 1822.

Número 6. Pernambuco: Tipografia Nacional, 1822.

Número 9. Recife: Tipografia Nacional, 1822. 


\section{SEGARREGA}

Todos os números extraídos do Acervo digital da Biblioteca Brasiliana e Guita e José Mindlin da Universidade de São Paulo.

Números 1 e 2. Pernambuco: Oficina do Trem de Pernambuco, 1821.

Números 3 e 4. Pernambuco: Oficina do Trem de Pernambuco, 1822.

Números 5 ao 15. Pernambuco: Tipografia Nacional, 1822.

Números 16 ao 26. Pernambuco: Tipografia Cavalcante \& Cia, 1822.

Números 27 e 28. Pernambuco: Tipografia Nacional, 1822.

\section{O MARIBONDO}

Todos os números extraídos do Acervo digital da Biblioteca Brasiliana e Guita e José Mindlin da Universidade de São Paulo.

Números 1, 2, 3, 4 e 5. Pernambuco: Tipografia Cavalcante e Companhia, 1822.

\section{O CONCILIADOR NACIONAL}

Todos os números extraídos do Acervo digital da Biblioteca Brasiliana e Guita e José Mindlin da Universidade de São Paulo.

Número 8. Pernambuco: Tipografia Cavalcante e Companhia, 1822.

Números 9, 10, 14 e 18. Pernambuco, Tipografia Cavalcante e Companhia, 1823.

\section{ESCUDO DA LIBERDADE DO BRAZIL}

Números 1 ao 16. Pernambuco: Tipografia Cavalcante e Companhia, 1823.

Biblioteca Nacional. Obras Raras. Loc. p 19, 3, 50.

\section{SENTINELA DA LIBERDADE.}

Coleção de textos de Cipriano Barata, publicada em: MOREL, Marco (org.). Sentinela da Liberdade e outros escritos. São Paulo: Edusp. 2008.

\section{O TYPHIS PERNAMBUCANO.}

Coleção integral do periódico dirigido por Frei Joaquim do Amor Divino Caneca, publicada em. CHACON, Vamireh, e LEITE NETO, Leonardo (org.). Edição comemorativa do $160^{\circ}$ aniversário da Confederação do equador. Brasília: Centro Gráfico do Senado Federal, 1984.

\section{O LIBERAL}

Números 19, 20, 21 e 22. Pernambuco: Tipografia de Miranda e Companhia, 1824. Arquivo Público Estadual Jordão Emerenciano, Loc. MR - XIX L - 15a. 